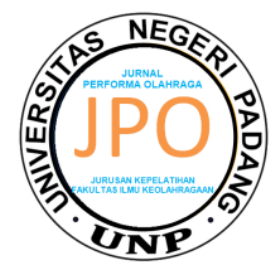

Jurnal Performa Olahraga

ISSN Online : 2714-660X ISSN Cetak : 2528-6102

Journal Homepage : http://performa.ppj.unp.ac.id/index.php/kepel

Volume 5 Nomor 2, 2020, Hlm 1-8

https://doi.org/10.24036/xxxxxxxx

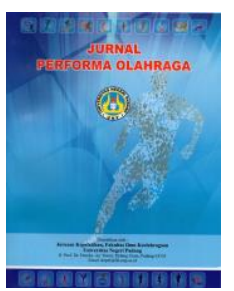

PENGEMBANGAN VARIASI LATIHAN TENDANGAN MAWASHI GERI JODAN PADA ATLET KARATE KATEGORI KUMITE

Yoki Afriandy Rangkuti ${ }^{1}$, Nona Novita ${ }^{2}$, Eko Purnomo ${ }^{3}$, Rizkei Kurniawan $^{4}$

${ }^{1,2,4}$ Pendidikan Jasmani, Fakultas Keguruan Ilmu Pendidikan,Universitas Samudra, Indonesia

${ }^{3}$ Pendidikan Kepelatihan Olahraga,Fakultas Ilmu Keolahragaan,

Universitas Negeri Padang, Indonesia.

\section{Informasi Artikel}

Diterima 2020-12-12

Direvisi 2020-12-19

Dipublikasikan 2020-12-27

\section{Keyword:}

First keyword

Second keyword

Third keyword

Fourth keyword

Fifth keyword

\begin{abstract}
Mawashi Geri Jodan kick is one of the kicks that is often taken when competing with a score of 3 points (ipon). Mawashi Geri Jodan has a sideto-top kick towards the head from the side, how to do a mawashi geri jodan kick by lifting his straight leg up and aimed at the side target of the head. When practicing the Mawashi Geri kick, the athlete feels bored and lacks enthusiasm due to the lack of variation in the training provided by the coach. The purpose of this study was to determine the effectiveness of the variation of Geri Jodan's mawashi kick training and to determine the accuracy of the kicks in the training variations developed for kumite athletes. The method used in this research is the research and development method or Research and Development $(R \& D)$ by conducting trials in small groups and large group trials. The development of this variation of the mawashi geri jodan kick training exercise has been effective because the products offered have passed the product validation stage carried out by experts and phase I product trials have been carried out with an average value of $65.47 \%$ in the "Eligible" category. II with an average score of $85 \%$ in the "Very Appropriate" category. The accuracy of the kick training variations of the mawashi geri jodan kick in the small group trial was in the "Fair" and "Good" categories. And in the large group trial it fell into the "Good" and "Very Good" categories.
\end{abstract}

(c) 2020 The Authors. Published by Universitas Negeri Padang.

This is an open access article under the CC BY-NC-SA license (https://creativecommons.org/licenses/by-nc-sa/4.0/

\title{
Penulis Korespondensi:
}

Yoki Afriandy Rangkuti

Universitas Samudra

Email: yokikenshi@unsam.ac.id

\section{PENDAHULUAN}

Olahraga prestasi adalah olahraga yang membina dan mengembangkan olahragawan secara terencana, berjenjang, dan berkelanjutan melalui kompetisi untuk mencapai prestasi dengan dukungan ilmu pengetahuan dan teknologi keolahragaan. Artinya dalam membina dan mengembangkan atlet untuk meraih prestasi yang gemilang, harus melalui proses yang terencana dalam mempersiapkan semua aspek yang mendukung sesuai kebutuhan cabang olahraga yang ditekuni, berjenjang sesuai tahapan usia dan berkelanjutan melalui kompetisi. Untuk memperoleh itu semua harus didukung ilmu pengetahuan dan teknologi keolahrgaan. Contohnya 


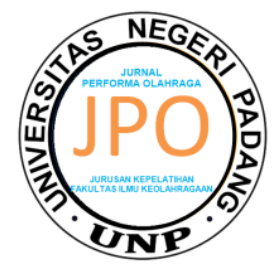

Jurnal Performa Olahraga

ISSN Online : 2714-660X ISSN Cetak : 2528-6102

Journal Homepage : http://performa.ppj.unp.ac.id/index.php/kepel

Volume 5 Nomor 2, 2020, Hlm 1-8

https://doi.org/10.24036/xxxxxxxx

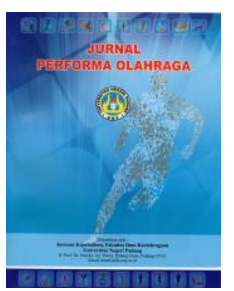

mengembangkan metode latihan yang kreatif dan menyenangkan untuk memaksimalkan kemampuan teknik dasar pada atlet dalam suatu cabang olahraga.

Karate merupakan satu dari sekian banyak olahraga khususnya beladiri yang cukup lama berkembang di Indonesia. Karate juga merupakan olahraga prestasi yang di pertandingkan baik di tingkat Daerah, Nasional maupun Internasional. Teknik dasar karate terdiri dari kuda-kuda (dachi), pukulan (zuki), tangkisan (uke), dan tendangan (geri). Tujuan utama melatih teknik dasar yaitu memperoleh pemahaman tentang bagaimana tubuh bergerak untuk menghasilkan daya sebanyak mungkin dengan upaya yang minimal.

Tendangan Mawashi Geri Jodan merupakan salah satu tendangan yang sering dilakukan saat bertanding dengan memperoleh nilai 3 poin (ipon), dalam tendangan Ushiro Geri memiliki arah lintasan menusuk kebelakang, sedangkan Mawashi Geri Jodan ini arahnya ke samping depan atas ke arah kepala dari arah samping, cara melakukan tendangan mawashi geri jodan dengan mengangkat kaki lurus ke atas dan di arahkan ke sasaran samping kepala. Agar dapat memperoleh kecepatan dan ketepatan dalam melakukan tendangan Mawashi Geri Jodan maka di perlukan latihan yang terprogram dan dilakukan secara berulang-ulang agar menghasilkan teknik tendangan yang bagus.

Keterampilan dalam melakukan tendangan tersebut dapat dilakukan setiap atlet dengan melalui suatu proses latihan agar dapat menguasai tendangan Mawashi Geri Jodan dengan baik. Keterampilan tersebut dapat dikuasai dan diperoleh bila dipelajari atau dilatih secara terus menerus melalui program training atau bimbingan yang didukung oleh kemampuan dasar yang sudah dimiliki, jika kemampuan dasar digabung dengan bimbingan secara intensif tentu akan dapat menghasilkan sesuatu yang bermanfaat dan bernilai.

Pada setiap pertandingan yang dilaksanakan akan dikategorikan menjadi beberapa kelompok, mulai dari anak Usia Dini (Usia 8-9 Tahun), Pra Pemula (Usia 10-11 Tahun), Pemula (Usia 12-13 Tahun), Kadet (Usia 14-15 Tahun), Junior (Usia 16-17 Tahun), Under21 (Usia 18-20 Tahun), dan Senior (Usia 20+). Sehingga pada saat berlatih peneliti melihat Pelatih juga menjadikan beberapa kelompok latihan pada saat latihan dengan materi yang berbeda-beda karena materi yang diberikan mempunyai tingkat kesulitan yang berbeda pula.

Dari hasil pengamatan yang diperoleh selama melakukan pengamatan, pada saat atlet berlatih di dojo bentuk latihan yang biasa dilakukan oleh atlet adalah melakukan tendangan mawashi geri jodan menggunakan target samsak., melakukan tendangan mawashi geri jodan bergantian dengan teman. dan melakukan tendangan mawashi geri jodan sendiri-sendiri. Permasalahan yang sering dijumpai pada saat berlatih melakukan tendangan mawashi geri atlet merasa jenuh dan kurang bersemangat karena kurangnya variasi latihan yang diberikan oleh pelatih.

\section{METODE}

Penelitian ini merupakan penelitian pengembangan atau Reseach and development ( $R \& D$ ). Menurut Sugiyono (2018:297) Metode penelitian dan pengembangan atau dalam bahasa Inggris research and development $(R \& D)$ adalah metode penelitian yang digunakan untuk menghasilkan produk tertentu, dan menguji keefektifan produk tersebut. Menurut Arikunto (2017:203) metode penelitian adalah cara yang digunakan oleh peneliti dalam mengumpulkan data penelitiannya.

Prosedur yang digunakan dalam penelitian ini menggunakan metode penelitian dan pengembangan atau Research and Development (R\&D) dari sugiyono (2018:298) yang menyatakan bahwa langkah-langkah penelitian dan pengembangan dijelaskan pada bagan di bawah ini. 


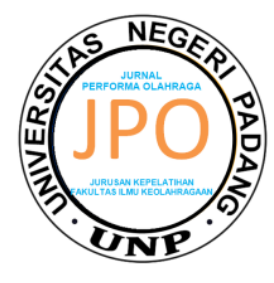

Jurnal Performa Olahraga

ISSN Online : 2714-660X ISSN Cetak : 2528-6102

Journal Homepage : http://performa.ppj.unp.ac.id/index.php/kepel

Volume 5 Nomor 2, 2020, Hlm 1-8

https://doi.org/10.24036/xxxxxxxx

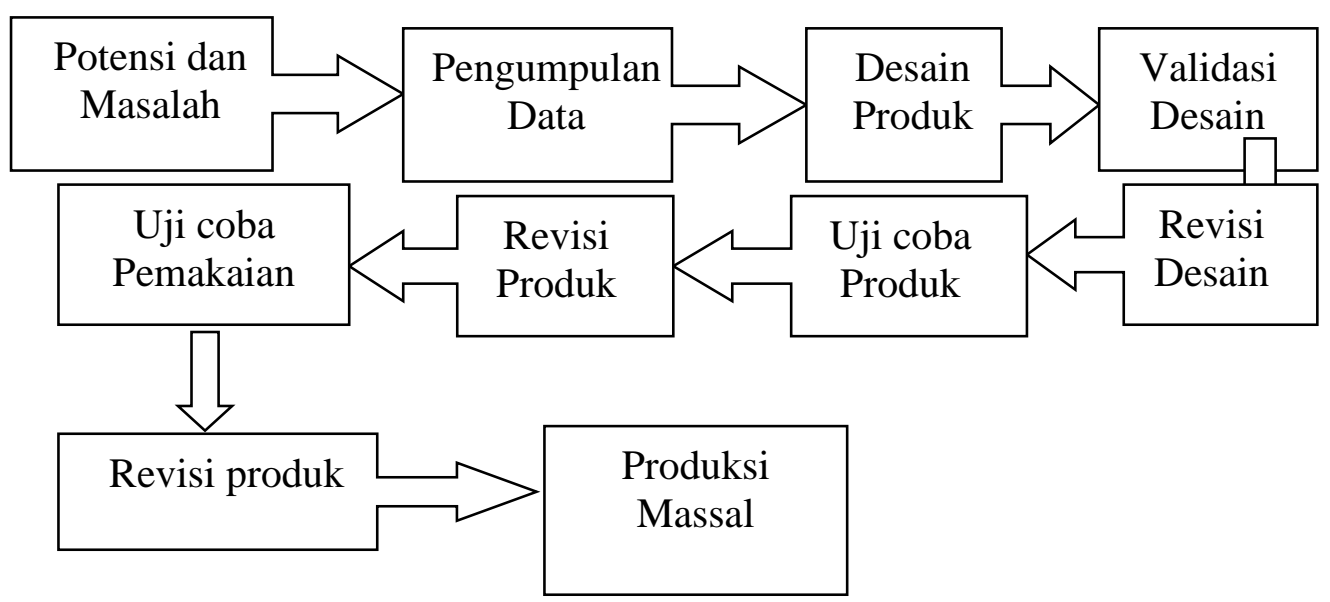

Langkah-langkah penggunaan metode Research and development

(Sumber : Sugiyono, $2018: 298$ )

Secara prosedur penelitian pengembangan ini harus melewati beberapa tahapan, seperti yang sudah dijelaskan diataskan. Namun penelitian pengembangan ini hanya menggunakan beberapa tahap saja mulai dari tahap potensi dan masalah, pengumpulan data, desain produk, validasi, revisi, dan uji coba tahap 1 dan tahap 2. Penelitian ini tidak sampai pada tahap produksi massal. Adapun produk yang dihasilkan dalam penelitian ini adalah variasi latihan tendangan mawashi geri jodan pada atlet kumite.

Tahap-tahap yang digunakan dalam penelitian ini di sesuaikan dengan keterbatasan waktu penelitian, maka dari itu dalam penelitian pengembangan ini peneliti hanya mengambil beberapa langkah saja. Hasil pengamatan dari masalah yang ada kemudian peneliti melakukan pengumpulan informasi dari atlet dan pelatih, setelah itu peneliti melanjutkan dengan membuat rancangan dan desain berupa beberapa produk pengembangan variasi latihan tendangan mawashi geri untuk atlet saat latihan dengan harapan dapat menghilangkan kejenuhan saat berlatih dan dapat membantu meningkatkan prestasi saat bertanding. Sebelum melakukan uji coba produk yang dihasilkan, produk-produk tersebut akan divalidasikan terlebih dahulu oleh beberapa ahli sebelum dilakukan uji coba pada kelompok kecil dan kelompok besar.

Adapun tahap-tahap yang dikemukan oleh sugiyono (2018:298) yang dilakukan dalam melakukan penelitian dan pengembangan atau research and development (R\&D) dapat dijabarkan sebagai berikut:

1) Identifikasi Potensi dan Masalah

Peneliti melakukan analisis kebutuhan berupa observasi atau pengamatan dan melakukan wawancara kepada atlet dan pelatih guna memperoleh informasi awal untuk melakukan penelitian. Pengamatan dilakukan pada saat atlet melakukan latihan kumite, sesudah melakukan pengamatan peneliti melakukan wawancara terhadap beberapa atlet guna menentukan penelitian yang akan dikembangkan. 


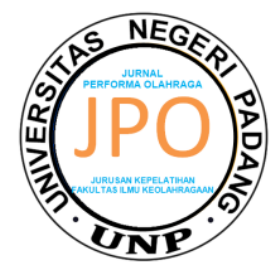

Jurnal Performa Olahraga

ISSN Online : 2714-660X ISSN Cetak : 2528-6102

Journal Homepage : http://performa.ppj.unp.ac.id/index.php/kepel

Volume 5 Nomor 2, 2020, Hlm 1-8

https://doi.org/10.24036/xxxxxxxx

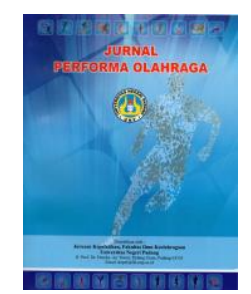

2) Pengumpulan Data

Peneliti melakukan pengumpulan data dengan melakukan identifikasi masalah dan mengumpulkan informasi dari atlet yang telah di wawancarai kemudian merencanakan pengembangan berikutnya.

3) Desain Produk

Dari hasil pengamatan dan informasi yang telah di peroleh, peneliti mulai merancang beberapa desain produk. Dimana proses pembuatan produk ini dilakukan dengan mencari referensi dan inspirasi dari berbagai sumber melalui buku dan internet, hasil dari ide-ide yang timbul kemudian di desain untuk menjadi suatu konsep.

4) Validasi Desain

Setelah melakukan tahap desain produk selesai, kemudian peneliti melanjutkan ke tahap validasi dengan beberapa produk variasi latihan yang telah di rancang dan akan dikembangkan untuk diberikan penilaian kelayakan produk, masukan maupun perbaikan dari Ahli materi dan ahli media.

a.Ahli materi

Ahli materi yang dimaksud dalam penelitian ini adalah orang yang ahli dalam suatu bidang, seperti pelatih karate dan wasit karate untuk menentukan dan mengetahui apakah variasi latihan yang akan diberikan ini sudah layak dan sesuai dengan materi yang akan diberikan pada atlet.

b. Ahli media

Ahli media yang dimaksud dalam penelitian ini adalah orang yang ahli dalam suatu bidang seperti Dosen/pakar/ahli yang biasa menangani dalam hal media pembelajaran. Validasi dilakukan oleh ahli media untuk menilai kelayakan beberapa produk yang akan di uji cobakan.

5) Revisi Desain

Dilakukannya revisi desain setelah adanya hasil penilaian kelayakan produk awal yang dilakukan oleh ahli untuk menghasilkan produk selanjutnya agar lebih baik lagi.

6) Uji Coba Produk

Uji coba produk dilakukan setelah mendapatkan nilai kelayakan oleh ahli bahwa produk sudah bisa di uji cobakan di Dojo, kemudian peneliti melakukan uji coba kelompok kecil dengan tujuan memperoleh data agar menghasilkan kualitas produk.

Uji coba produk dilakukan pada tahap uji coba kelompok kecil yang bertujuan mendapatkan informasi serta masukan penyempurnaan produk yang akan dikembangkan. Uji coba dilakukan dengan tujuan untuk menyempurnakan produk.

\section{Teknik Analisis Data}

Pada penelitian pengembangan ini teknik analisis data yang digunakan adalah teknik analisis deskriptif kuantitatif dengan persentase. Teknik ini di gunakan untuk menganalisa data kuantitatif yang di peroleh dari hasil uji coba bentuk variasi latihan Tendangan Mawashi Geri Jodan pada atlet kumite Usia 14 Tahun sampai 17 Tahun Di Dojo SMP Negeri 3 Langsa. Setiap validator akan memiliki nilai yang berbeda, Ketiga nilai validator terhadap satu model dirataratakan dan itulah yang menjadi acuan apakah model tersebut digunakan atau tidak. Rumus untuk mengolah tanggapan atau evaluasi dihitung menggunakan rumus persentase menurut (Purwanto, 2012: 76) yaitu :

$$
\text { Rumus : } P=\frac{\text { JumlahNilaiDiperoleh }}{\text { JumlahTotal }} \times 100 \%
$$




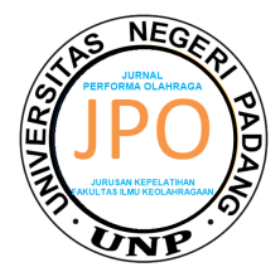

Jurnal Performa Olahraga

ISSN Online : 2714-660X ISSN Cetak : 2528-6102

Journal Homepage : http://performa.ppj.unp.ac.id/index.php/kepel

Volume 5 Nomor 2, 2020, Hlm 1-8

https://doi.org/10.24036/xxxxxxxx

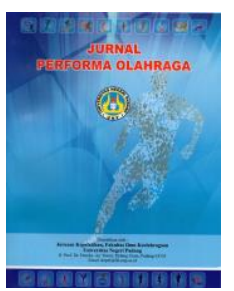

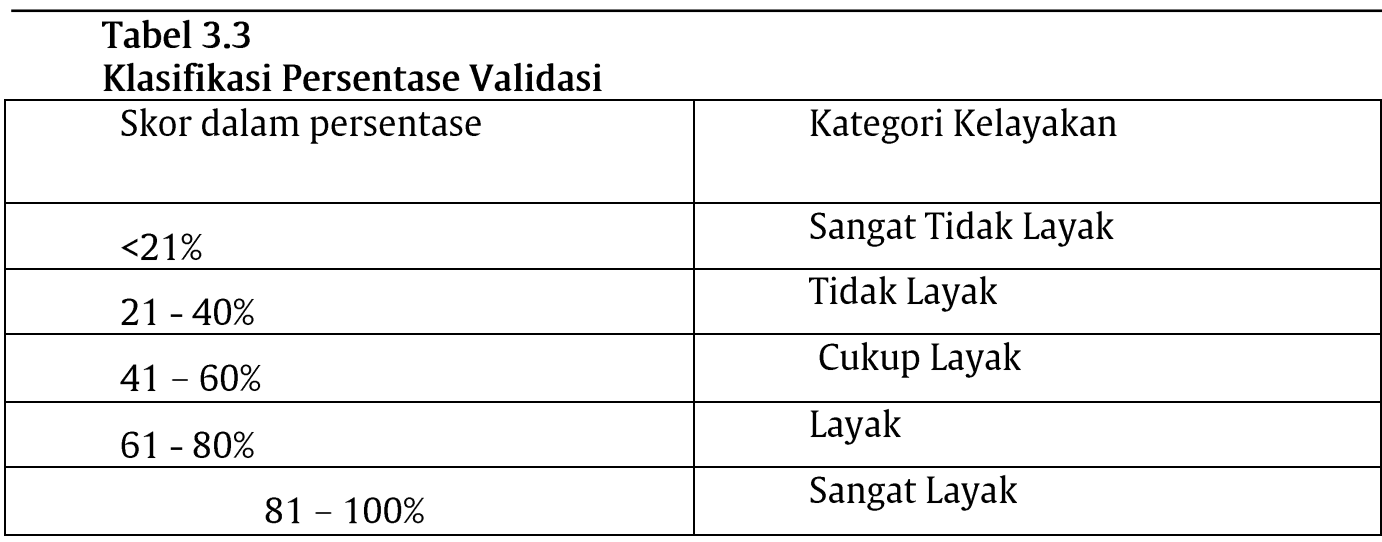

Sumber: Arikunto dalam Ernawati \& Sukardiyono (2017:207)

\section{HASIL DAN PEMBAHASAN}

\section{Hasil Penelitian}

Pada penelitian ini peneliti melakukan studi pendahuluan dengan pengumpulan data yaitu observasi, dan wawancara. Berdasarkan dari hasil wawancara kurangnya variasi latihan dan program latihan yang monoton menyebabkan atlet merasa kurang bersemangat saat berlatih dengan materi yang telah diberikan pada saat latihan. Dibawah ini adalah draf atau desain awal dari 7 variasi yang ditawarkan dalam bentuk produk variasi latihan mawashi geri jodan, variasi latihan dengan menggunakan alat-alat sederhana dan mudah ditemui seperti, cangkir, selang, isolasi hitam, karet, cone, dan kursi.

Setelah melihat draf atau desain awal dari 7 variasi produk yang ditawarkan, selanjutnya ahli memberikan saran dan masukan agar bisa direvisi untuk melanjutkan ke tahap selanjutnya, ada 2 rancangan produk yang tidak digunakan dan ada 5 produk yang di revisi sesuai saran dan masukan ahli agar produk tersebut menjadi lebih bermakna.

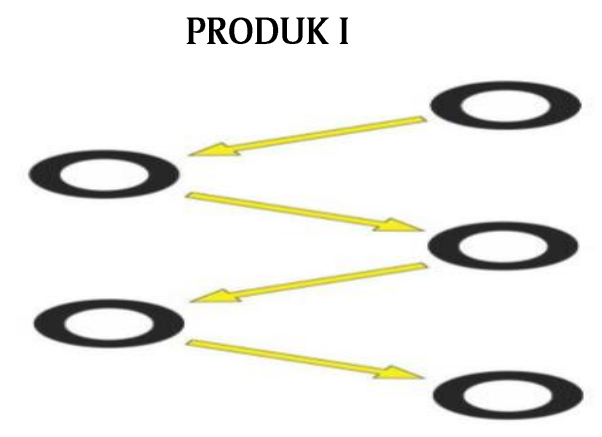

Langkah-langkah melakukan variasi ini adalah sebagai berikut :

1. Atlet harus berbaris dalam kelompok untuk menunggu giliran melakukan variasi latihan setelah teman yang ada didepannya.

2. Atlet bersiap-siap melakukan latihan variasi.

3. Saat mendengar aba-aba yang diberikan dari peneliti, atlet harus melompat dari lingkaran satu ke lingkaran lainnya dengan menggunakan satu kaki.

4. Apabila sudah sampai pada sasaran atau samsak, atlet melakukan tendangan mawashi geri jodan pada sasaran. 


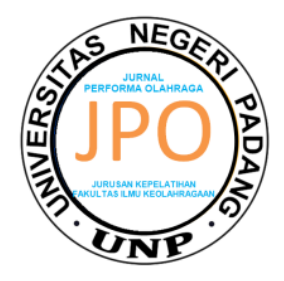

Jurnal Performa Olahraga

ISSN Online : 2714-660X ISSN Cetak : 2528-6102

Journal Homepage : http://performa.ppj.unp.ac.id/index.php/kepel

Volume 5 Nomor 2, 2020, Hlm 1-8

https://doi.org/10.24036/xxxxxxxx

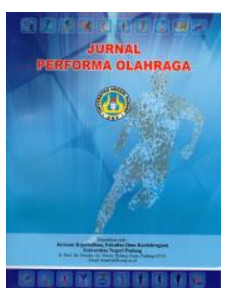

\section{Produk II}

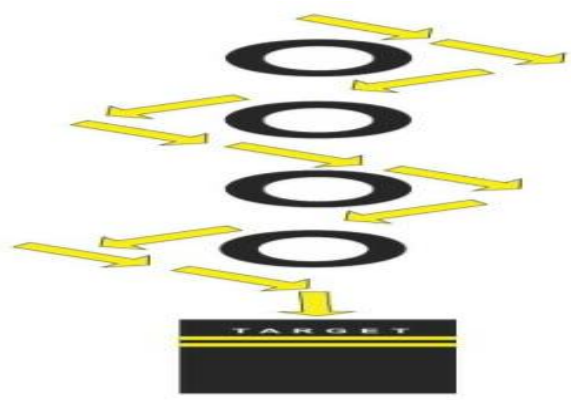

Langkah-langkah melakukan variasi ini adalah sebagai berikut :

1. Atlet harus berbaris dalam kelompok untuk menunggu giliran melakukan variasi latihan setelah teman yang ada didepannya.

2. Atlet bersiap-siap melakukan latihan variasi.

3. Saat mendengar aba-aba yang diberikan dari peneliti, atlet berlari melewati rintangan cone dengan secara zig-zag.

Apabila sudah sampai pada sasaran atau samsak, atlet melakukan tendangan mawashi geri jodan pada sasaran.

\section{PRODUK III}

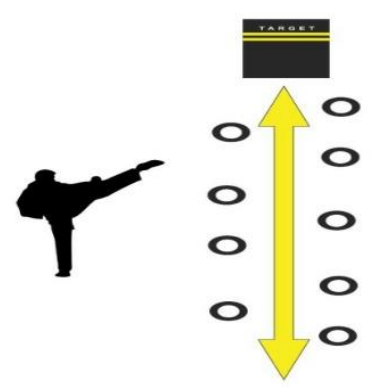

Langkah-langkah melakukan variasi ini adalah sebagai berikut :

1. Atlet harus berbaris dalam kelompok untuk menunggu giliran melakukan variasi latihan.

2. Atlet bersiap-siap melakukan latihan variasi.

3. Saat mendengar aba-aba yang diberikan dari peneliti, atlet melakukan stepping dengan satu kaki sementara satu kakinya dilontarkan untuk melewati garis lurus.

4. Apabila sudah sampai pada sasaran atau samsak, atlet melakukan tendangan mawashi geri jodan pada sasaran.

\section{PRODUK IV}

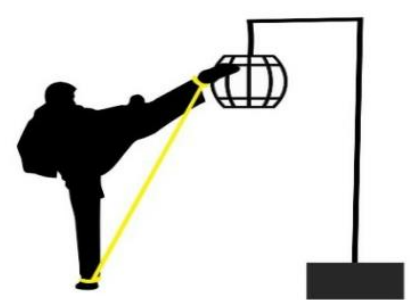




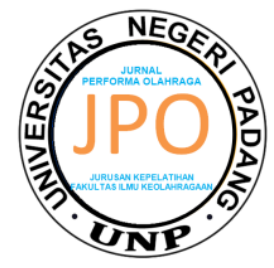

Jurnal Performa Olahraga

ISSN Online : 2714-660X ISSN Cetak : 2528-6102

Journal Homepage : http://performa.ppj.unp.ac.id/index.php/kepel

Volume 5 Nomor 2, 2020, Hlm 1-8

https://doi.org/10.24036/xxxxxxxx

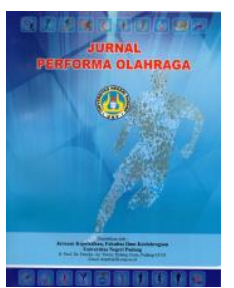

Langkah-langkah melakukan variasi ini adalah sebagai berikut :

1. Atlet harus berbaris dalam kelompok untuk menunggu giliran melakukan variasi latihan.

2. Atlet bersiap-siap melakukan latihan variasi.

3. Saat mendengar aba-aba yang diberikan dari peneliti, atlet melakukan tendangan pada sasaran menggunakan kaki yang di ikat dengan karet.

PRODUK V

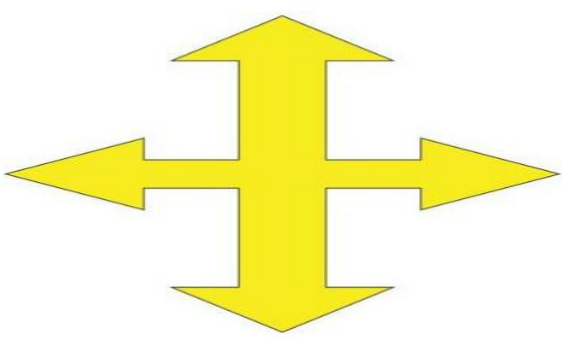

Langkah-langkah melakukan variasi ini adalah sebagai berikut :

1. Atlet harus berbaris dalam kelompok untuk menunggu giliran melakukan variasi latihan.

2. Atlet bersiap-siap melakukan latihan variasi.

3. Saat mendengar aba-aba yang diberikan dari peneliti, atlet berlari menuju ke empat arah sasaran dimana setiap arah memiliki sasaran tendangan mawashi geri jodan.

\section{Revisi produk}

Produk yang akan dikembangkan juga perlu di revisi. Revisi produk tersebut harus melalui proses validasi oleh ahli. Proses validasi dilakukan guna untuk melihat apakah produk variasi latihan yang akan dikembangkan layak untuk di uji cobakan. Setelah melalui proses validasi ahli tahap I (kelompok kecil), dari 7 produk awal yang di tawarkan ternyata hanya 5 produk yang layak untuk di uji cobakan pada tahap II (Kelompok Besar).

Berikut ini adalah gambar/bentuk dari 5 produk yang telah diperbaiki sesuai dengan saran dan masukan ahli yang akan diuji cobakan ke tahap II (Kelompok Besar):

1) Elastis kick

Pada tahap I (kelompok kecil) hasil dari saran dan masukan Ahli terhadap produk Elastis kick ini adalah, Agar dapat dilakukan dengan mudah dan tidak memakan waktu serta menyesuaikan kondisi dan tempat latihan, sebaiknya karet yang di ikat pada kaki atlet yang akan melakukan tendangan dipegang oleh atlet yang berada dibarisan belakang secara bergantian. Gambar diatas adalah dokumentasi setelah peneliti merevisi produk dari saran dan masukan para Ahli.

2) Sasaran mata angin

Pada tahap I (Kelompok Kecil) hasil dari saran dan masukan Ahli terhadap produk Sasaran Mata Angin adalah, produknya sudah bagus, namun pada saat pelaksaan sebaiknya dilakukan dengan stepping untuk menuju ke setiap arah sasaran yang telah ditentukan. Gambar diatas adalah dokumentasi setelah peneliti merevisi produk dari saran dan masukan Ahli. 


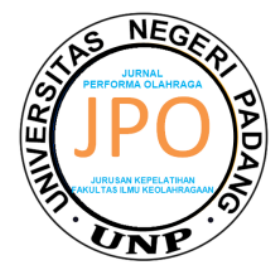

Jurnal Performa Olahraga

ISSN Online : 2714-660X ISSN Cetak : 2528-6102

Journal Homepage : http://performa.ppj.unp.ac.id/index.php/kepel

Volume 5 Nomor 2, 2020, Hlm 1-8

https://doi.org/10.24036/xxxxxxxx

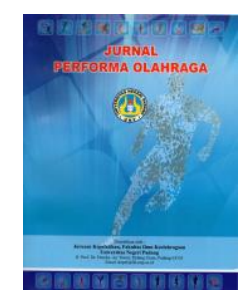

3) Lingkaran Kancil

Pada produk ini di tahap I (Kelomok Kecil) mendapatkan saran dan masukan dari Ahli terhadap Produk Lingkaran Kancil adalah, Jarak antara lingkaran satu dengan lingkaran lainnya jangan terlalu dekat agar atlet bisa membentuk kuda-kuda dan melatih tungkai kaki. Gambar diatas merupakan dokumentasi setelah dilakukan revisi dari saran dan masukan Ahli.

4) Garis Lontar

Produk ini di tahap I (Kelompok Kecil) mendapatkan saran dan masukan dari Ahli pada produk Garis Lontar adalah, untuk produk sudah bagus namun agar hasil yang didapatkan dari produk ini lebih bagus lagi, sebaiknya saat melakukan variasi latihan ini angkatan kaki di angkat setinggi dada. Gambar diatas merupakan dokumentasi setelah dilakukan revisi dari saran dan masukan Ahli.

5) Stepping zigzag Kick

Pada tahah I (Kelompok Kecil) mendapatkan saran dan masukan dari ahli terhadap produk Stepping Zigzag Kick adalah, pada produk ini sebaiknya jangan berlari zigzag, tapi dengan menggunakan stepping agar dapat produk yang dihasilkan lebih baik lagi.

Dari hasil saran dan masukan Ahli yang telah dijabarkan diatas dapat disimpulkan bahwa hampir dari setiap produk dan alat-alat yang digunakan tidak ada yang harus di revisi, namun pada saat pelaksaannya saja gerakannya banyak diberikan saran dan masukan dari Ahli.

\section{Data Hasil Uji Coba}

\section{Uji Coba Tahap I (Kelompok Kecil)}

Uji coba tahap I merupakan tindak lanjut dalam penelitian ini guna sebagai pengujian produk Variasi Latihan Tendangan Mawashi Geri Jodan serta untuk mendapatkan saran dan masukan. Uji coba tahap I ini dilakukan di Dojo KKI Bunga Jati dengan subjek uji cobanya adalah atlet kumite usia 14 tahun - 17 tahun yang berjumlah 10 orang, dengan hasil sebagai berikut : Berdasarkan hasil penilaian pada tabel diatas saat uji coba kelompok kecil dapat dilihat bahwa dari 10 atlet, hanya ada 6 (Enam) orang atlet mendapatkan nilai 73, 73, 71, 76, 76, dan 76, yang berada pada kategori "Baik", dan ada 4 (Empat) orang atlet yang mendapatkan nilai 70, 69, 66, dan 73, yang berada dalam kategori "Cukup".

\section{Uji Coba Tahap II (Kelompok Besar)}

Uji coba kelompok besar ini dilakukan di Dojo Lemkari Kota Langsa tehadap subjek penelitian 15 (Lima Belas) orang atlet Kumite yang berusia 14 (Empat Belas) tahun - 17 (Tujuh Belas) tahun dengan melakukan penerapan Variasi Latihan Tendangan Mawashi Geri Jodan yang telah divalidasi dan diperbaiki dari saran dan masukan yang diberikan pada sebelumnya. Dengan hasil sebagai berikut : Dari hasil penilaian pada tabel diatas pada uji coba kelompok besar dapat dilihat dari 15 atlet yang menjadi subjek uji coba bahwa 9 atlet mendapatkan nilai 93, 91, 92, 93, 93, 93, 94, 93, dengan kategori "Baik Sekali". Sedangkan 6 orang atlet mendapatkan nilai 90, 88, 90, 80, 83, 81, dengan kategori "Baik".

Dari hasil yang diperoleh setelah melakukan tahap-tahap yang harus dilalui dapat disimpulkan bahwa variasi latihan tendangan mawashi geri jodan telah berhasil dikuasai oleh atlet dan efektif diberikan kepada atlet kumite usia 14 tahun sampai 17 tahun.

\section{Pembahasan}

Pengembangan variasi latihan tendangan mawashi geri jodan ini dibuat dan dirancang untuk penambahan materi latihan atlet kumite karate yang di desain menjadi sebuah produk 
berupa variasi latihan. Produk variasi latihan tendangan mawashi geri jodan ini ditujukan pada atlet kumite usia 14 tahun sampai 17 tahun. Penelitian ini meggunakan metode yang dikembangkan oleh Sugiyono, karena dari langkah-langkah penelitiannya cocok untuk membuat suatu produk yang ingin dikembangkan, Penelitian ini bertujuan untuk menghasilkan produk yaitu variasi latihan tendangan mawashi geri jodan guna membantu atlet pada saat latihan tendangan mawashi geri jodan di Dojo.

Setelah produk awal dihasilkan selanjutnya produk akan dievaluasi oleh para ahli melalui validasi dan di ujicoba pada atlet. Tahap validasi yang dilakukan ini melewati dua tahap validasi yaitu Validasi Tahap I dan Validasi Tahap II. Pada validasi Tahap I ahli materi dan ahli media memberikan saran-saran perbaikan pada produk yang akan dikembangkan. Setelah melakukan perbaikan dari saran dan masukan para ahli kemudian produk divalidasikan kembali pada Tahap II sampai produk dinyatakan boleh untuk di uji cobakan.

Pada validasi tahap I yang diberikan ahli materi dan ahli media memperoleh nilai $75 \%$, 83,33\%, 75\%, 83\%, 33,33\%, 75\%, 33,33\% dengan rata-rata 65,47\% dalam kategori "Layak" dengan saran perbaikan. Setelah melakukan perbaikan dari saran dan masukan yang diberikan pada tahap I, Kemudian dilakukan kembali validasi tahap II dengan nilai yang diberikan adalah 91,67\%, 83,33\%, 91,67\%, 75\%, 83,33\% dengan nilai rata-rata 85\% dengan kategori "Sangat Layak" untuk di ujicobakan.

Pada uji coba kelompok kecil yang dilakukan di Dojo KKI Bunga Jati dapat dilihat pada tabel nilai yang diperoleh atlet pada saat melakukan tendangan yang berada pada kategori "Cukup" dengan perolehan nilai 70, 69, 66, dan 73 dan kategori "Baik" dengan memperoleh nilai 73, 73, 71, 76, 76, dan 76. Dan pada uji coba kelompok besar yang dilakukan di Dojo Lemkari Kota Langsa dapat dilihat pada tabel nilai yang diperoleh atlet pada saat melakukan tendangan dengan penerapan pengembangan variasi latihan memperoleh nilai $90,88,90,80,83,81$, dengan kategori "Baik". Dan nilai 93, 91, 92, 93, 93, 93, 94, 93, dengan kategori "Baik Sekali".

Dari hasil penelitian yang telah dilakukan, dari 7 produk awal yang ditawarkan hanya 5 produk yang layak untuk diuji coba, telah melalui tahap validasi dan dilakukan uji coba pada kelompok kecil dan kelompok besar maka dapat disimpulkan dari 5 produk yang telah di uji coba produk tersebut layak dan efektif diterapkan pada latihan tendangan mawashi geri jodan untuk atlet kumite.

Dari 2 produk yang tidak layak digunakan dapat ditarik kesimpulan bahwa pada produk variasi cangkir fokus dan kursi seimbang tidak efektif digunakan pada saat latihan karena tendangan yang dilakukan tidak tepat sasaran dan membutuhkan waktu yang lama untuk menyusun cangkir-cangkir yang jatuh, sehingga produk dinyatakan "Tidak Layak" digunakan.

Pembahasan difokuskan pada mengaitkan data dan hasil analisisnya dengan permasalahan atau tujuan penelitian dan konteks teoretis yang lebih luas. Dapat juga pembahasan merupakan jawaban pertanyaan mengapa ditemukan fakta seperti pada data.

Pembahasan ditulis melekat dengan data yang dibahas. Pembahasan diusahakan tidak terpisah dengan data yang dibahas.

\section{KESIMPULAN}

Berdasarkan hasil penelitian tentang Pengembangan variasi latihan Tendangan Mawashi Geri Jodan pada atlet kumite Usia 14 Tahun sampai 17 Tahun Di Dojo SMP Negeri 3 Langsa. dapat disimpulkan sebagai berikut:

1. Pengembangan variasi latihan tendangan mawashi geri jodan ini sudah efektif karena produk yang ditawarkan sudah melewati tahap validasi produk yang dilakukan para ahli 


\section{Jurnal Performa Olahraga}

ISSN Online : 2714-660X ISSN Cetak : 2528-6102

Journal Homepage : http://performa.ppj.unp.ac.id/index.php/kepel

Volume 5 Nomor 2, 2020, Hlm 1-8

https://doi.org/10.24036/xxxxxxxx

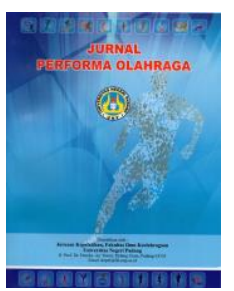

dan telah dilakukan uji coba produk. Pada validasi tahap I mendapatkan nilai rata-rata $65,47 \%$ dalam kategori "Cukup Baik/Cukup Layak". Dan pada validasi tahap II mendapatkan nilai rata-rata $85 \%$ dengan kategori "Baik/Layak"

2. $\quad$ Ketepatan tendangan pada pengembangan variasi latihan tendangan mawashi geri jodan pada atlet kumite yang dilakukan pada uji coba kelompok kecil dan uji coba kelompok besar, dengan hasil yang didapatkan pada uji coba kelompok kecil masuk dalam kategori "Cukup" dan "Baik". Dan hasil yang didapatkan pada uji coba kelompok besar dengan penerapan variasi latihan masuk dalam kategori "Baik" dan "Baik Sekali".

\section{DAFTAR PUSTAKA}

Ambarukmi, dkk.Pelatihan Pelatih Fisik Level 1. Jakarta: Kementrian Pemuda dan Olahraga.2007.

Arikunto, Suharsimi.Prosedur Penelitian Suatu Pendekatan Praktik. PT Rineka Cipta. Yogyakarta.2017

Asim.Model Pembelajaran.(2002). Jakarta: Kencana Media.

Bompa, T.(2009). Theory and Methodology of Training. Dubuque: Hunt Publishing Compani.

Budiwanto, S.(2012). metodologi Latihan Olahraga. Malang: UNM.

Degeng. Media Pembelajaran. Jakarta: Rineka Cipta.2002

Djoko Pekik.(2002).Dasar Kepelatihan Yogyakarta : FIK UNY.

Harsono.(2006). Coaching dan Aspek Psikologis dalam Coaching. CV. Tambal Kurnia. Jakarta.

Nossek. Dasar-dasar Kepelatihan Olahraga. Malang: UNM.2012

Pate, et al.(2012). Dasar-dasar IImiah Kepelatihan. Semarang. IKIP Semarang. Pres.

Pratomo,(2013). Box Jump, Depth Jump Sprint, Power Otot Tungkai pada Olahraga Pencak silat. Zahr Publishing.

Purba,(2016). Panduan Praktis Penyusunan Program Latihan. Jakarta: PT Raja Grafindo Persada.

Sabeth Muchsin.(1979). Best Karate Comprehensive. Yogyakarta: Pustaka Pelajar.

Sagitarius.Modul Karate. Bandung: FPOK/IKIP Bandung.2008.

Simbolon Bermanhot.(2016). Latihan Dan Melatih Karateka II Teknik-Taktik Karate. Pangururan: UWAIS Inspirasi Indonesia.

Sugiyono. Metode Penelitian Kuantitatif, Kualitatif, Dan R\&D. Bandung: Alfabeta.2018.

-,Sukadiyanto Dan Muluk,(2011). Dangsina.Pengantar Teori Dan Metodologi Melatih Fisik.

Penerbit Lubuk Agung. Bandung.

Sukmadinata,(2005). Metode Penelitian Pendidikan. Jakarta: Rineka Cipta.

Wahid, Abdul. (2007). Shotokan. Jakarta: PT Raja Grafindo Persada. 
